\title{
Comparisons of Group-Size, Composition and Movement of Herbivorous Reef Fish in Jamaica and Grand Cayman Island
}

\author{
Layla Al-Shaer1 $^{*}$ (D), Andrew Bloch${ }^{1}$, Matthew Draud ${ }^{2}$, Brandon Baumann1, Murray Itzkowitz ${ }^{1}$ \\ ${ }^{1}$ Department of Biological Sciences, Lehigh University, Bethlehem, PA, USA \\ ${ }^{2}$ College of Arts and Sciences, Siena Heights University, Adrian, MI, USA \\ Email: ${ }^{\star}$ Lta312@Lehigh.edu
}

How to cite this paper: Al-Shaer, L., Bloch, A., Draud, M., Baumann, B. and Itzkowitz, M. (2020) Comparisons of Group-Size, Composition and Movement of Herbivorous Reef Fish in Jamaica and Grand Cayman Island. Open Journal of Marine Science, 10, 1-15. https://doi.org/10.4236/ojms.2020.101001

Received: October 21, 2019

Accepted: December 10, 2019

Published: December 13, 2019

Copyright $\odot 2020$ by author(s) and Scientific Research Publishing Inc. This work is licensed under the Creative Commons Attribution International License (CC BY 4.0).

http://creativecommons.org/licenses/by/4.0/

\begin{abstract}
The decline in herbivorous fishes is an important contributing factor to the degradation of coral reefs, because their reduction contributes to macro algae overgrowth, which can have harmful effects on corals. Herbivorous fish often form mixed-species groups to locate foraging sites and for defense. The movements and compositions of these groups are dependent on the relative numbers of different species present. Some species, such as the striped parrotfish (Scarus iserti) and ocean surgeonfish (Acanthurus bahianus), serve as core species that lead mixed-species groups. Others, such as the redband (Sparisoma aurofrenatum) and stoplight parrotfishes (Sparisoma viride), follow core species as their associates. Despite the potential importance and abundance of mixed-species groups on reefs, little attention has been given to their composition and movements. Our intent was to determine whether the social dynamics of mixed-species groups in Jamaica were similar to those of Grand Cayman. The overall sizes of mixed-species groups were smaller in Grand Cayman. Focal striped parrotfish in Grand Cayman formed smaller groups, changed composition less, and moved less frequently than in Jamaica. Although probably more abundant than striped parrotfish, the ocean surgeonfish in Grand Cayman did not function as a core species but rather attached themselves as associates to the smaller striped parrotfish groups. Redband parrotfish moved less often in Grand Cayman, and appeared to be more dependent on striped parrotfish groups than stoplight parrotfish. While previous studies on herbivorous reef fish have shown that changes in foraging patterns can change with location, perhaps related to structural heterogeneity and resource distribution, this study illustrates that social interactions between common members of mixed-species groups also change. We suggest that the intra and interspecific social interactions in Grand Cayman are less
\end{abstract}


attuned to finding erratically located high quality resources than those in Jamaica. Other plausible explanations are also considered.

\section{Keywords}

Coral Decline, Foraging Behavior, Algae-Grazing, Herbivore, Scaridae, Acanthuridae

\section{Introduction}

Coral reefs are widely viewed as in decline [1] [2] [3] [4] [5], and the overfishing of algae-grazing fishes is often considered an important contributing factor [5] [6] [7] [8] but see [9]. The reduction of these fishes contributes to macro algae overgrowth, resulting in the killing and/or retarding of slower growing corals [10]. While not restricting themselves to fishes, Ogden and Lobel [11] were one of the first to relate the effectiveness of reef fish on algae distribution and abundance. Subsequent studies, have placed increasing emphasis on the types and amounts of algae grazed by the most common species of herbivores e.g. [12]-[17]. Burkepile and Hay [18] [19] showed that groups with a mixture of herbivorous fish species, including parrotfish, were best able to retard the growth of algae and therefore protect corals.

Few studies have considered the interactions among fish species that are common members of mixed-species groups on reefs, but rather have focused on the foraging behavior of one species at a time e.g. [20] [21] [22] [23] [24]. Itzkowitz [25] [26] followed the foraging movements of mixed-species groups in Jamaica as they meandered around the reefs in order to quantify how the movements of one species influenced the others. He determined that the most abundant species led the group (termed "core" species), with all other species following (termed "associate" species). Within groups it was not unusual for the relative abundance of a species to change and, consequently, leadership changed as well. Typically, the core species fluctuated between two species, the striped parrotfish (Scarus iserti) and the ocean surgeonfish (Acanthurus bahianus), with both feeding in open areas on the uniformly abundant turf-filamentous algae. Most associate species used the core species group as a way to move safely through open areas on their way to the macro-algae on large rubble and coral.

The core species commonly fractured into smaller groups or individuals while, at the same time, others joined the group. Typically, individuals that left a group quickly joined another foraging group [25] [26]. The continuous formation, fractionation, and reformation of the core groups suggested a foraging tactic designed to test the foraging success of other groups. In an experimental manipulation, Itzkowitz [27] illustrated that these gregarious species were adept at finding unpredictable high-quality food patches that were haphazardly discovered by a single individual. Once a food source was discovered, the group numbers would quickly increase and then decrease as the food source depleted. Thus, 
while these different species often appear to graze on different species of algae, they do appear interdependent on how they move around the reef.

It is possible that the type of social systems used by mixed-species groups in Jamaica may have been designed to exploit a habitat and a community of fishes unique to that island. For example, other studies have noted that coral reef herbivores do change their movements based on changes in habitat that were structurally different e.g. [16] [24] [28]. Here we compare the mixed-species groups in Jamaica and Grand Cayman reefs to see how comparable the social dynamics are between these two islands. We attempted to de-emphasize habitat structure differences by selecting sites that seemed visually similar on the two islands. Instead, we were drawn to this comparison because a previous study [29] suggested differences in the relative numbers of individuals of each species between these locations (see below).

We documented the movements of four herbivorous species that were prominent members of mixed-species groups in Jamaica in 1977 [26]: striped parrotfish and ocean surgeonfish which had served as the core species (leaders of groups) and the stoplight parrotfish (Sparisoma viride)and the redband parrotfish (Sparisoma aurofrenatum) which were common associate species (followers of groups). Draud and Itzkowitz [29] while considering body sizes of these four species between the two islands, qualitatively observed that the striped parrotfish numbers appeared considerably lower in Grand Cayman than in Jamaica while the other three species were quite similar. If this difference remained consistent (it was also noted in [26] and [29]), changes in the dynamics of the mixed-species groups may result. We were especially interested in determining whether fewer striped parrotfish correlated with changes in their numbers within groups and/or changes in the likelihood that they would serve as a core for other species.

\section{Methods}

\subsection{Description of Back-Reef Habitats}

The climate of the two Caribbean islands surveyed is tropical, with temperatures ranging from warm to hot year-round and at least one wet season. Data was collected during the spring and summer of 2016 in Grand Cayman and Jamaica respectively. Jamaica's site $\left(18^{\circ} 28^{\prime} 13.3^{\prime \prime} \mathrm{N} 77^{\circ} 24^{\prime} 48.2^{\prime \prime} \mathrm{W}\right)$ was restricted to the west back reef of Discovery Bay, while Grand Cayman's sites $\left(19^{\circ} 21^{\prime} 10.6^{\prime \prime} \mathrm{N}\right.$ $81^{\circ} 12^{\prime} 31.4^{\prime \prime} \mathrm{W}$ ) were centered around the back reefs of Mahogany Point, approximately midway along the north coast (Figure 1 ). We selected these sites because they are both protected from intense spear and trap fishing, and both are on the north coast of both islands. In both locations, we followed groups in the back-reef beginning near the reef crest where there was an approximate depth of $1-2 \mathrm{~m}$. The reef crests were approximately $50-150 \mathrm{~m}$ from the shore. Because previous studies on herbivorous coral reef fish emphasized that habitat structure influences foraging behavior [16] [24] [28], we selected sites at both 


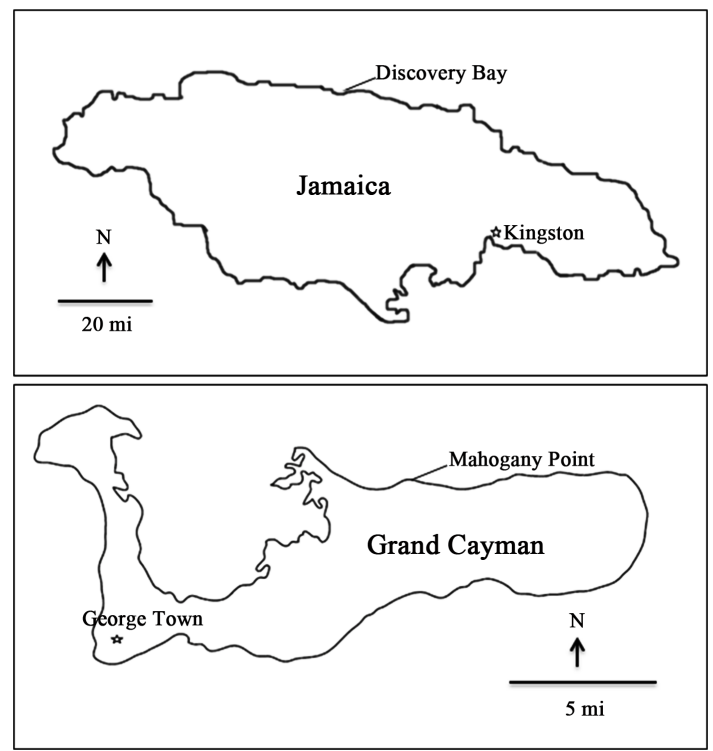

Figure 1. Study sites map.

island locations whose substrate composition was visually similar. To characterize the substrata, we recorded the substrate type present every $1 \mathrm{~m}$ using line transects that were placed adjacent and parallel to the reef crests in both locations (Figure 2). In Jamaica, transect data were collected along $300 \mathrm{~m}$ of the west back reef of Discovery Bay. In Grand Cayman, $300 \mathrm{~m}$ of transect data was collected from three adjacent sites near Mahogany Point where data was co $(900 \mathrm{~m}$ total). We considered 4 general categories of substrata; live coral, small rubble (dead coral rocks less than $20 \mathrm{~cm}$ across), large rubble (dead coral rocks usually much greater than $20 \mathrm{~cm}$ across) and turtle grass (Thalassia testudinum). We avoided transects over bare sand because this habitat rarely supported algae grazing groups, but otherwise positioned transects so as to cover the areas where group data was collected. In Jamaica, live coral was extremely rare ( $0 \%$ of transect), while turtle grass was extremely common ( $49 \%$ of transect). Most importantly, based on our transect data, our sites at both island locations had similar amounts of large rubble (9\% and $13 \%$ in Jamaica and Grand Cayman respectively; see Figure 2); a habitat that has been shown to influence group size and movements [26].

\subsection{Selection of Focal Species and Data Collected}

Species were identified visually following the descriptions provided by Bohlke and Chaplin [30]. We followed the movement patterns of two core species, striped parrotfish and ocean surgeonfish, and two associate species, stoplight and redband parrotfish. We set out to have each of these four species serve as the focal species in 30 replicate groups in both Jamaica and Grand Cayman (Total $\mathrm{n}$ $=240$ replicate groups, or 120 groups/island). However, in Jamaica, there was only $\mathrm{n}=29$ striped parrotfish groups and $\mathrm{n}=29$ ocean surgeonfish groups, making the total $n=118$ in Jamaica. To avoid pseudo replication, investigators 


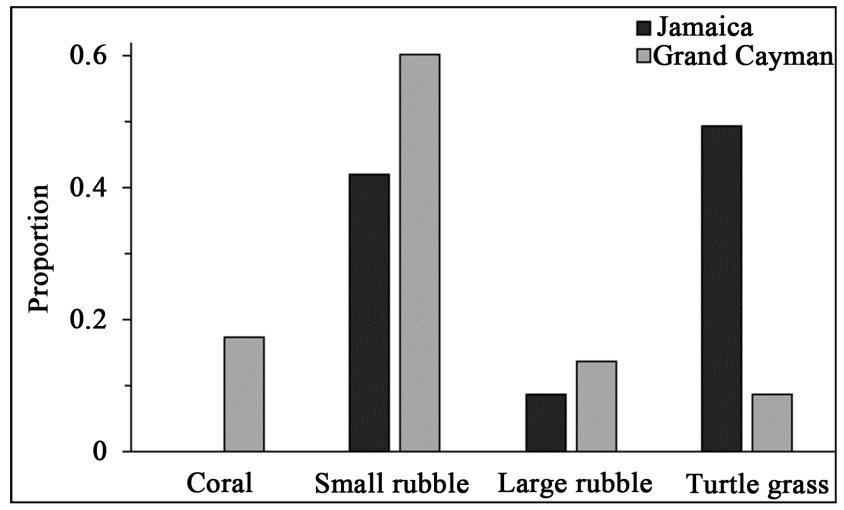

Figure 2. Substrates in Jamaica and Grand Cayman.

roughly estimated the focal species groups present in a section of reef, recorded data from those replicate groups, then moved along the coast to an unsurveyed section of reef before collecting more replicates. Investigators never resampled a previously visited area. As a focal species moved, it was often joined by one or more of the other three species under our consideration. These heterospecific individuals were termed non-focal. For example, if we were following a striped parrotfish, it was designated as the focal species, while any other species of interest that joined (i.e. ocean surgeonfish, stoplight parrotfish, and redband parrotfish) were designated as non-focal species. Similarly, when we started out following a stoplight parrotfish, we termed it as a focal species and all others, irrespective of their numbers, were now termed the non-focal species. In instances where the focal species joined other heterospecific groups, the original species was still considered to be "focal" and observations continued; if/when that new heterospecific group split, investigators continued to observe the original focal species. In Jamaica and Grand Cayman, each replicate group was haphazardly selected by locating either an individual or a group of conspecific individuals belonging to one of the four species of interest. For each replicate, we recorded the number of times the individual or group changed position on the reef and changed composition over a 10-minute observation period. Composition changes were determined by recording the number of focal and non-focal individuals, from the four species considered, that were present after each group movement. This allowed us to track the proportions of each species as a group moved around the reef.

\subsection{Feeding Habits}

While this study was concerned with the social interactions between and within species, all four species were engaged in foraging. For this reason, we provide the below descriptions to further aid in describing the similarities and differences between species.

Striped parrotfish: Itzkowitz [26] observed that striped parrotfish largely fed in open areas feeding on low profile algae using a rapid series of nips. They did eat large macroalgae, typically growing in damselfish territories, when it became 
available. Cardoso et al. [31] mentioned that this species "...took small bites, removing foraging targets by close cropping". See also McAfee and Morgan [16].

Ocean surgeonfish: Few studies have described their food habitats, but Itzkowitz [26] observed that they fed in the same areas and with the same type of macro-algae foraging behavior as the striped parrotfish. Similar to the striped parrotfish, they will also eat macro algae in damselfish territories [32].

Stoplight and Redband Parrotfish: Both species selectively graze large macroalgae attached to rocks and appear to avoid eating the filamentous algae preferred by the striped parrotfish [16] [26] [33]. Sparisoma spp. do forage on turtle grass [12]

\subsection{Statistical Analyses}

Group Size and Composition Analyses. For each replicate group, the total number of individuals belonging to our four species of interest was quantified (herein referred to as "total group size"). Total group size was calculated by summing the total number of individuals belonging to our four species of interest, and then dividing by the number of times a group changed position over the observation period (unless a group never changed position). Thus, the total group size of a species may refer to a group that never moved, a group that moved multiple times without any compositional changes occurring, or a group that moved many times and had total changes. A mixed ANOVA was used to determine if differences in group composition existed based on the non-focal species present, the focal species followed, and island location. The number of individuals observed within replicate groups from our four species of interest served as the within-subject factor (non-focal composition), and focal species and island location were used as between-subject factors. Non-focal composition data violated sphericity, so Greenhouse-Geisser corrections and Bonferroni post-hoc analyses were performed.

Focal Fish Group Size and Composition Changes: The number of focal individuals in each group was totaled and then divided by the number of position changes in order to calculate focal fish group size for each replicate (unless a group never changed position). For each location, we used Pearson correlations to test if the number of conspecific individuals within core species groups (i.e. focal striped parrotfish and ocean surgeonfish replicates) was related to group composition changes.

Focal Species and Group Movement. A two-way ANOVA was used to test for an interaction effect between island location and focal species on the number of group movements observed. Only the interaction was of interest, so a custom type-III sum of squares model was created that tested only the interaction effect. A Pearson correlation compared total group size to group movements.

\section{Results}

\subsection{Group Sizes}

Total group size (focal + non-focal individuals from our four species of interest) 
was similar regardless of which focal species was being followed (Figure 3; Mean \pm SE: striped parrotfish $=6.92 \pm 0.46$, ocean surgeonfish $=6.08 \pm 0.46$, redband parrotfish $=5.89 \pm 0.46$, stoplight parrotfish $=5.75 \pm 0.46 ; F_{3,230}=1.30, p=0.28$, $\left.\eta_{p}^{2}=0.02\right)$. Groups were larger overall in Jamaica than in Grand Cayman (Figure 3; Mean \pm SE: Jamaica $=8.50 \pm 0.33$, Grand Cayman $=3.82 \pm 0.32 ; F_{1,230}$ $\left.=103.61, p<0.001, \eta_{p}^{2}=0.31\right)$. There was no significant interaction between focal species followed and island location on total group size (Figure $3 ; F_{3,230}=$ $\left.0.38, p=0.77, \eta_{p}^{2}=0.005\right)$.

\subsection{Group Composition by Island Location}

Regardless of focal species or island location, there was a main effect of non-focal fish composition which indicated that the four species of interest were not equally represented in replicate groups (Figure 4; Mean \pm SE: striped parrotfish $=3.20 \pm 0.18$, ocean surgeonfish $=1.48 \pm 0.12$, redband parrotfish $=0.82$ \pm 0.03 , stoplight parrotfish $=0.66 \pm 0.03 ; F_{1.7388 .3}=114.46, p<0.001, \eta_{p}^{2}=$ $0.33)$. There was also a significant interaction between island location and non-focal fish composition (Figure $4 ; F_{1.7388 .31}=38.05, p<0.001, \eta_{p}^{2}=0.14$ ) which we will describe. In Jamaica (Figure 4(a)), striped parrotfish maintained larger conspecific numbers (4.67 \pm 0.26 individuals) within replicate groups than ocean surgeonfish $(2.21 \pm 0.16$ individuals $)$, stoplight parrotfish $(0.84 \pm 0.05$ individuals), and redband parrotfish $(0.77 \pm 0.04$ individuals $)$; regardless of the focal species being followed (all $p<0.001$ ). Groups in Jamaica were also composed of greater numbers of ocean surgeonfish than redband parrotfish (mean diff. $=1.37 \pm 0.17, p<0.001$ ) and stoplight parrotfish (mean diff. $=1.44 \pm 0.17, p$ $<0.001$ ), which did not differ from each other (mean diff $=0.07 \pm 0.06 ; p=$ 1.00). As in Jamaica, striped parrotfish in Grand Cayman (Figure 4(b)) were significantly more prevalent within groups ( $1.73 \pm 0.26$ individuals) compared to the other three species of interest (ocean surgeonfish: $0.74 \pm 0.16$ individuals, $p=$ 0.007; redband parrotfish: $0.79 \pm 0.05$ individuals, $p=0.002$; stoplight parrotfish: $0.55 \pm 0.04$ individuals, $p<0.001)$. Ocean surgeonfish were not more prevalent

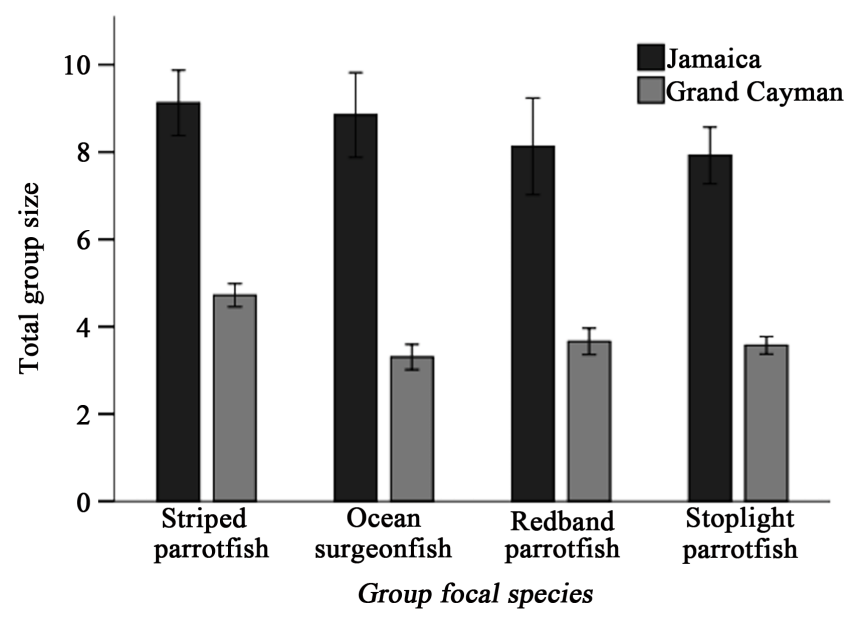

Figure 3. Total group size. 


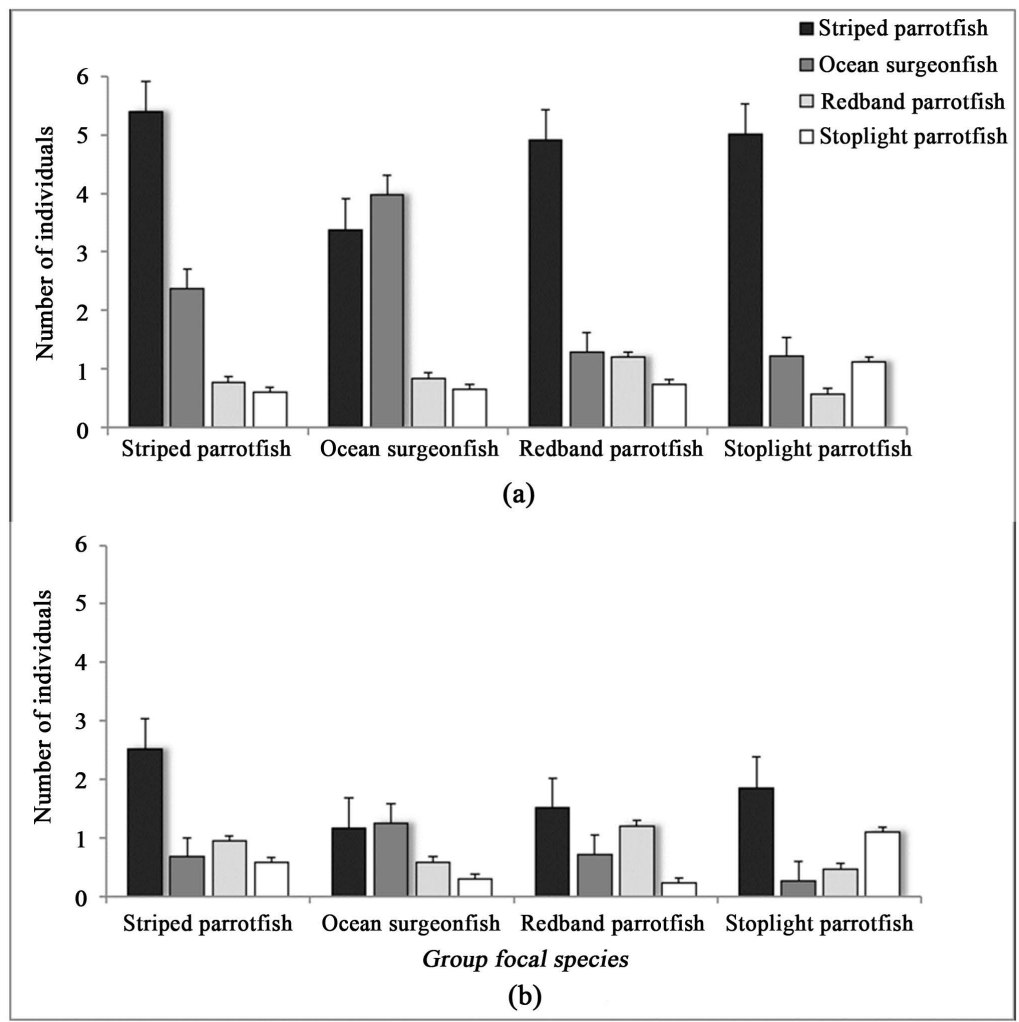

Figure 4. Group composition by focal species and location. (a) Jamaica; (b) Grand Cayman.

than redband (mean diff. $=-0.05 \pm 0.17$ ) or stoplight parrotfish (mean diff. $=$ $0.19 \pm 0.17$ ), the latter of which were observed less than redband parrotfish (mean diff. $=-0.24 \pm 0.06, p<0.001$ ).

Comparing between Jamaica and Grand Cayman (Figure 4(a) \& Figure 4(b)), the numbers of striped parrotfish, ocean surgeonfish and stoplight parrotfish observed within groups was significantly larger in Jamaica (striped parrotfish: mean diff. $=2.95 \pm 0.37, p<0.001$; ocean surgeonfish: mean diff. $=1.47 \pm$ $0.23, p<0.001$; stoplight parrotfish: mean diff. $=0.22 \pm 0.06, p<0.001)$ while there was no significant difference between the two locales in redband parrotfish group composition (mean diff. $=0.05 \pm 0.07, p=0.455$ ).

\subsection{Group Composition by Focal Species}

There was a significant interaction between focal species followed and non-focal composition (Figure $4 ; F_{5.1388 .3}=8.89, p<0.001, \eta_{p}^{2}=0.10$ ) which we will describe here. Regardless of island location, focal striped parrotfish groups were composed of more striped parrotfish ( $3.95 \pm 0.37$ individuals) than all other species (ocean surgeonfish: $1.53 \pm 0.23, p<0.001$; redband parrotfish: $0.86 \pm 0.07, p$ $<0.001$; stoplight parrotfish: $0.59 \pm 0.06, p<0.001$ ). Focal striped parrotfish groups also consisted of more ocean surgeonfish than redband parrotfish (mean diff. $=0.67 \pm 0.25, p=0.043$ ) or stoplight parrotfish (mean diff. $=0.94 \pm 0.24, p$ $=0.001$ ). In focal ocean surgeonfish groups, striped parrotfish also represented a 
large component $(2.27 \pm 0.37$ individuals) but were not significantly different from the numbers of focal ocean surgeonfish $(2.61 \pm 0.23$ individuals $)$ observed $(p=1.00)$. Focal ocean surgeonfish groups did consist of more ocean surgeonfish than both redband parrotfish $(0.71 \pm 0.07$ individuals, $p<0.001)$ and stoplight parrotfish $(0.47 \pm 0.06$ individuals, $p<0.001)$, which did differ in number from each other (mean diff. $=0.24 \pm 0.08, p=0.02$ ). As non-focal individuals, redband parrotfish and stoplight parrotfish were rarely more than one individual per group for any focal species (redband parrotfish: mean $\pm \mathrm{SE}=0.82 \pm 0.03$ individuals; stoplight parrotfish: mean $\pm \mathrm{SE}=0.66 \pm 0.03$ individuals). There was no three-way interaction between focal species, non-focal composition, and island location on composition (Figure 4; $F_{5.07,388.31}=2.13, p=0.06, \eta_{p}^{2}=0.03$ ).

\subsection{Focal Group Size and Composition Changes}

A comparison between the number of conspecifics present within striped parrotfish and ocean surgeonfish focal groups versus the number of composition changes within those groups was analyzed by island location. There was no relationship between striped parrotfish individuals and composition changes within striped parrotfish focal groups in Jamaica $(r=0.34, p=0.07)$, but there was a positive correlation in Grand Cayman $(r=0.39, p=0.04)$. In contrast, there was a positive relationship between ocean surgeonfish individuals and composition changes within ocean surgeonfish focal groups in Jamaica $(r=0.44, p=0.02)$, but no correlation in Grand Cayman $(r=-0.009, p=0.96)$.

\subsection{Focal Species and Group Movement}

There was a significant interaction between the focal species followed and island location when it came to how often group movements occurred (Figure 5; Mean \pm SE: Jamaica: striped parrotfish $=30.48 \pm 1.86$, ocean surgeonfish $=32.03 \pm$ 1.86 , redband parrotfish $=26.67 \pm 1.83$, stoplight parrotfish $=29.00 \pm 1.83$, Grand Cayman: striped parrotfish $=21.82 \pm 1.83$, ocean surgeonfish $=28.63 \pm$ 1.83 , redband parrotfish $=19.53 \pm 1.83$, stoplight parrotfish $=26.033 \pm 1.83$; $\left.F_{7,230}=5.37, p<0.001, \eta_{p}^{2}=0.14\right)$. Striped parrotfish groups moved more often in Jamaica compared to those in Grand Cayman (mean diff. $=8.67 \pm 2.61 ; p=$ 0.001 ), and the same was true of redband parrotfish groups (mean diff. $=7.13 \pm$ $2.59 ; p=0.006$ ). The other two species did not vary by location (ocean surgeonfish: mean diff. $=3.40 \pm 2.61, p=0.19$; stoplight parrotfish: mean diff. $=2.97 \pm$ $2.59, p=0.25)$. In Jamaica, there was no difference in movements between species (all comparisons $p \geq 0.25$ ). In Grand Cayman, ocean surgeonfish focal groups moved more often than redband parrotfish (mean diff. $=9.10 \pm 2.59, p=0.003$ ), but not striped parrotfish (mean diff. $=6.82 \pm 2.59, p=0.054$ ) or stoplight parrotfish focal groups (mean diff. $=2.60 \pm 2.59, p=1.00$ ). All other pairwise comparisons in Grand Cayman were not significant (all $p \geq 0.074$ ). There was no correlation between total group size and number of group movements across island locations ( $r=0.014, p=0.84$ ). 


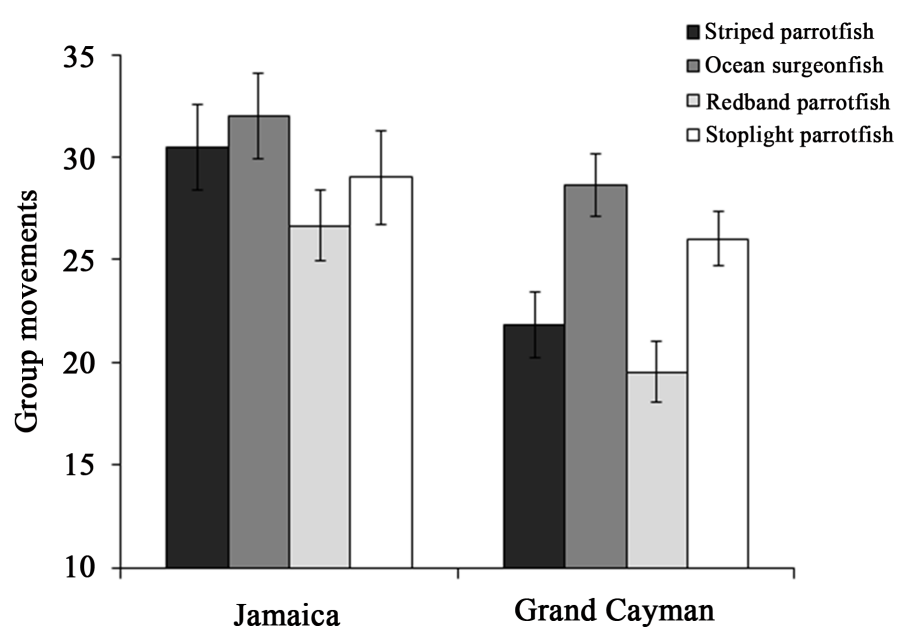

Figure 5. Group movements.

\section{Discussion}

In Jamaica, the mixed-species groups were composed of core species that typically lead (e.g. striped parrotfish and ocean surgeonfish) and associate species that follow (e.g. stoplight parrotfish and redband parrotfish) and were consistent with that observed over 40 years ago [26]. Striped parrotfish and ocean surgeonfish, core species, were the most numerous species in their mixed-species groups and both moved and changed composition similarly. The two associate species, stoplight and redband parrotfish, were also similar in their behavior by being either solitary or the sole representation of their species in their groups. However, in Grand Cayman the striped parrotfish formed smaller groups than in Jamaica while ocean surgeonfish primarily attached themselves to striped parrotfish groups. In both island locations, redband and stoplight parrotfish exhibited similar behavior, by being either solitary or the sole representative of their species in a mixed-species group, but the redband parrotfish moved less often than the stoplight parrotfish.

While we initially suspected that differences between Jamaica and Grand Cayman may be the result of fewer striped parrotfish in Grand Cayman, it was surprising that ocean surgeonfish, which showed the greatest behavioral difference, seemed quite common on both islands [29]. Furthermore, given the wide-ranging movements of both species, it remains unclear why striped parrotfish did not simply combine into larger groups as found in Jamaica and why ocean surgeonfish rarely developed the numbers that caused them to become a core species. Clearly, the differences that control group size on Jamaica for these two species changed on Grand Cayman.

Given the differences between the striped parrotfish and the ocean surgeonfish in Grand Cayman, it now seems unlikely that numbers of individuals in an area reflect the size of any single group. Wolf [34] observed that ocean surgeonfish forage more efficiently in groups making it unclear if both striped parrotfish and ocean surgeonfish have different foraging tactics in Grand Cayman. For 
example, rather than foraging efficiency per se, these groups might be designed to serve other functions. Foster [22] observed that large groups of herbivores can more readily gain access to and forage within damselfish territories. Territorial damselfish chase these mixed-species groups on both islands (pers obs), but perhaps territorial damselfish are less of an influence in our Grand Cayman study sites making large groups less important. Another possibility, is that the structural heterogeneity of Grand Cayman's reef may act to limit group size. Itzkowitz [26] suggested that very large groups fractionate as individuals take separate routes around large blocks of coral and rock and this could inhibit the formation of large groups. Similarly, Nash et al. [24] also suggested that foraging movements of mixed-species parrotfish groups on the Great Barrier Reef were influenced by the degree of habitat heterogeneity. As can be seen from our transect data, large rubble was a minor component in both Jamaica and Grand Cayman and thus should have minimal influence on group sizes or movements.

Besides group size and composition, we considered two additional components: number of compositional changes and the number of movements by a group. Itzkowitz [25] [26] suggested that both of these aspects appear related to inspecting the quality of food found by other groups. Several studies have indicated that the macro algae preferred by herbivorous fish do occur in patches and, not surprisingly, these patches appear to impact on the distribution of herbivores [28] [35] [36]. In this current study, we found that striped parrotfish had fewer compositional changes in Grand Cayman which, coupled with their smaller group size, might indicate that there was less need to continually search for new richer food areas or that such food was largely absent. A quantitative comparison of macro algae is required to consider this possibility but our observations did not indicate dramatic differences in algal patch quality or distribution.

Groups can protect individuals from predation (e.g. [21] [37]) and larger groups may provide more protection. In Grand Cayman, a reduction in predators might also explain why striped parrotfish groups were reduced in size and why ocean surgeonfish rarely formed groups. In regards to ocean surgeonfish, Wolf [34] observed that predation risk explains the correlation between reduced numbers and less feeding. It is unclear if the ocean surgeonfish in Grand Cayman are protected by following striped parrotfish as their associates. We observed no predation attacks on either island during this study or previous ones (e.g. [29]), but perhaps Grand Cayman had fewer predators than Jamaica.

Redband and stoplight parrotfish were quite similar in both island locations; they were either solitary or were the sole representative of their species in a mixed-species group. In Jamaica, they would attach themselves to striped parrotfish and, to a lesser extent, ocean surgeonfish. In Grand Cayman, the redband and stoplight parrotfish joined the smaller groups of striped parrotfish and only rarely joined ocean surgeonfish that did not have striped parrotfish as group members. In Jamaica, both species moved similarly while redband parrotfish 
moved less in Grand Cayman. This last point was the only indication that these two associate species foraged differently. It is possible that redband parrotfish depended more on striped parrotfish groups and thus moved less in Grand Cayman than stoplight parrotfish.

In summary, our results indicate that the group dynamics of both the striped parrotfish and the ocean surgeonfish were quite similar in Jamaica, but were quite different from each other in Grand Cayman. This divergence of the two species suggests that both species, but in particular the ocean surgeonfish, were not using conspecifics to locate high quality food (see [26] [27]) nor where they providing similar leadership to other species. The two associate species considered also changed in Grand Cayman, but to a lesser extent with the redband parrotfish seeming to become more reliant on the movements of the striped parrotfish. While previous studies on herbivores have been shown to change foraging patterns with changes in location, perhaps related to structural heterogeneity and resource distribution, this study illustrates that social interactions between common members of mixed-species groups also change.

\section{Acknowledgements}

We would like to thank the Discovery Bay Marine Laboratory in Discovery Bay, Jamaica for allowing us to use their facility.

\section{Conflicts of Interest}

The authors declare that they have no conflict of interest.

\section{Ethical Approval}

All applicable international, national, and/or institutional guidelines for the care and use of animals were followed.

\section{References}

[1] Bellwood, D.R., Hughes, T.P., Folke, C. and Nyström, M. (2004) Confronting the Coral Reef Crisis. Nature, 429, 827-833. https://doi.org/10.1038/nature02691

[2] Bruno, J.F. and Selig, E.R. (2007) Regional Decline of Coral Cover in the Indo-Pacific: Timing, Extent, and Subregional Comparisons. PLoS ONE, 2, e711. https://doi.org/10.1371/journal.pone.0000711

[3] Hoegh-Guldberg, O., Mumby, P.J., Hooten, A.J., Steneck, R.S., Greenfield, P., Gomez, E., Harvell, C.D., Sale, P.F., Edwards, A.J., Caldeira, K., Knowlton, N., Eakin, C.M., Iglesias-Prieto, R., Muthiga, N., Bradbury, R.H., Dubi, A. and Hatziolos, M.E. (2007) Coral Reefs under Rapid Climate Change and Ocean Acidification. Science, 318, 1737-1742. https://doi.org/10.1126/science.1152509

[4] De'ath, G., Fabricius, K.E., Sweatman, H. and Puotinen, M. (2012) The 27-Year Decline of Coral Cover on the Great Barrier Reef and Its Causes. Proceedings of the National Academy of Sciences, 109, 17995-17999. https://doi.org/10.1073/pnas.1208909109

[5] Hughes, T.P. (1994) Catastrophes, Phase-Shifts, and Large-Scale Degradation of a Caribbean Coral-Reef. Science, 265, 1547-1551. 
https://doi.org/10.1126/science.265.5178.1547

[6] Done, T.J. (1992) Phase Shifts in Coral Reef Communities and their Ecological Significance. Hydrobiologia, 247, 121-132. https://doi.org/10.1007/BF00008211

[7] Rogers, C.S. and Miller, J. (2006) Permanent "Phase Shifts" or Reversible Declines in Coral Cover? Lack of Recovery of Two Coral Reefs in St. John, US Virgin Islands. Marine Ecology Progress Series, 306, 103-114. https://doi.org/10.3354/meps306103

[8] Hughes, T.P., Graham, N.A.J., Jackson, J.B.C., Mumby, P.J. and Steneck, R.S. (2010) Rising to the Challenge of Sustaining Coral Reef Resilience. Trends in Ecology and Evolution, 25, 633-642. https://doi.org/10.1016/j.tree.2010.07.011

[9] Aronson, R.B. and Precht, W.F. (2006) Conservation, Precaution, and Caribbean Reefs. Coral Reefs, 25, 441-450. https://doi.org/10.1007/s00338-006-0122-9

[10] Mumby, P.J. (2009) Herbivory versus Corallivory: Are Parrotfish Good or Bad for Caribbean Coral Reefs? Coral Reefs, 28, 683-690. https://doi.org/10.1007/s00338-009-0501-0

[11] Ogden, J.C. and Lobel, P.S. (1978) The Role of Herbivorous Fishes and Urchins in Coral Reef Communities. Environmental Biology of Fishes, 3, 49-63. https://doi.org/10.1007/BF00006308

[12] Lewis, S.M. (1986) The Role of Herbivorous Fishes in the Organization of a Caribbean Reef Community. Ecology Monographs, 56, 183-200.

https://doi.org/10.2307/2937073

[13] Horn, M.H. (1989) Biology of Marine Herbivorous Fishes. Oceanography and Marine Biology an Annual Review, 27, 167-272.

[14] Targett, T.E. and Targett, N.M. (1990) Energetics of Food Selection by the Herbivorous Parrotfish Sparisoma radians: Roles of Assimilation Efficiency, Gut Evacuation Rate, and Algal Secondary Metabolites. Marine Ecology Progress Series, 66, 13-21. https://doi.org/10.3354/meps066013

[15] Bruggemann, J.H., van Oppen, M.J.H. and Breeman, A.M. (1994) Foraging by the Stoplight Parrotfish Sparisoma viride. I. Food Selection in Different, Socially Determined Habitats. Marine Ecology Progress Series, 106, 41-55. https://doi.org/10.3354/meps106041

[16] McAfee, S.T. and Morgan, S.G. (1996) Resource Use by Five Sympatric Parrotfishes in the San Blas Archipelago, Panama. Marine Biology, 125, 427-437.

[17] Hanmer, J., White, J.W. and Pawlik, J.R. (2017) Application of Diet Theory Reveals Context-Dependent Foraging Preferences in an Herbivorous Coral Reef Fish. Oecologia, 184, 127-137. https://doi.org/10.1007/s00442-017-3855-y

[18] Burkepile, D.E. and Hay, M.E. (2008) Herbivore Species Richness and Feeding Complementarity Affect Community Structure and Function on a Coral Reef. Proceedings of the National Academy of Sciences, 105, 16201-16206. https://doi.org/10.1073/pnas.0801946105

[19] Burkepile, D.E. and Hay, M.E. (2010) Impact of Herbivore Identity on Algal Succession and Coral Growth on a Coral Reef. PLoS ONE, 5, e8963. https://doi.org/10.1371/journal.pone.0008963

[20] Adam, T.C., Kelley, K., Ruttenberg, B.I. and Burkepile, D.E. (2015) Resource Partitioning along Multiple Niche Axes Drives Functional Diversity in Parrotfishes on Caribbean Coral Reefs. Community Ecology, 179, 1173-1185. https://doi.org/10.1007/s00442-015-3406-3

[21] Clifton, K.E. (1989) Territory Sharing by the Caribbean Striped Parrotfish. Scarus iserti: Patterns of Resource Abundance, Group Size and Behavior. Animal Beha- 
viour, 37, 90-103. https://doi.org/10.1016/0003-3472(89)90009-2

[22] Foster, S.A. (1985) Group Foraging by a Coral Reef Fish: Mechanism for Gaining Access to Defended Resources. Animal Behaviour, 33, 782-792. https://doi.org/10.1016/S0003-3472(85)80011-7

[23] Haley, F. (1984) Time-Budgeting and Foraging Strategy of the Stoplight Parrotfish Sparisoma viride Bonnaterre, in Jamaica. Journal of Experimental Marine Biology and Ecology, 83, 159-177. https://doi.org/10.1016/0022-0981(84)90043-1

[24] Nash, K.L., Graham, N.A.J., Januchowski-Hartley, F.A. and Bellwood, D.R. (2012) Influence of Habitat Condition and Competition of Foraging Behaviour of Parrotfishes. Marine Ecology and Progress Series, 457, 113-124. https://doi.org/10.3354/meps09742

[25] Itzkowitz, M. (1974) A Behavioural Reconnaissance of Some Jamaican Reef Fishes. Zoological Journal of the Linnean Society, 55, 87-118. https://doi.org/10.1111/j.1096-3642.1974.tb01589.x

[26] Itzkowitz, M. (1977) Social Dynamics of Mixed-Species Groups of Jamaican Reef Fishes. Behavioral Ecology and Sociobiology, 2, 361-384.

https://doi.org/10.1007/BF00299506

[27] Itzkowitz, M. (1980) Group Formation of Reef Fishes Induced through Food Provisioning. Biotropica, 12, 227-281. https://doi.org/10.2307/2387699

[28] Francini-Filhio, R.B., Ferreira, C.M., Coni, E.O.C. and De Moura, R.L. (2010) Foraging Activity of Roving Herbivorous Reef Fish (Acanthuridae and Scaridae) in Eastern Brazil: Influence of Resource Availability and Interference Competition. Journal of the Marine Biological Association, 90, 481-492. https://doi.org/10.1017/S0025315409991147

[29] Draud, M.J. and Itzkowitz, M. (2018) Have the Algae-Grazing Fish in the Back Reefs of Jamaica and Grand Cayman Changed in Size? A View across 36 Years. Open Journal of Marine Science, 8, 300-313. https://doi.org/10.4236/ojms.2018.82016

[30] Böhlke, J.E. and Chaplin, C.G.C. (1968) Fishes of the Bahamas and Adjacent Tropical Waters. University of Texas Press, Austin.

[31] Cardoso, S.C., Soares, M.C., Oxenford, H.A. and Côté, I.M. (2009) Interspecific Differences in Foraging Behaviour and Functional Role of Caribbean Parrotfish. Marine Biodiversity Records, 2, e148. https://doi.org/10.1017/S1755267209990662

[32] Lawson, G.L., Kramer, D.L. and Hunte, W. (1999) Size-Related Habitat Use and Schooling Behavior in Two Species of Surgeonfish (Acanthurus bahianus and $A$. coeruleus) on a Fringing Reef in Barbados, West Indies. Environmental Biology of Fishes, 54, 19-33.

[33] van Rooij, J.M., de Jong, E., Vaandrager, F. and Videler, J.J. (1996) Resource and Habitat Sharing by the Stoplight Parrotfish, Sparisoma viride, a Caribbean Reef Herbivore. Environmental Biology of Fishes, 47, 81-91. https://doi.org/10.1007/BF00002381

[34] Wolf, N.G. (1987) Schooling Tendency and Foraging Benefit in the Ocean Surgeonfish. Behavioral Ecology and Sociobiology, 21, 59-63. https://doi.org/10.1007/BF00324436

[35] Williams, I.D., Polunin, N.V.C. and Hendrick, V.J. (2001) Limits to Grazing by Herbivorous Fishes and the Impact of Low Coral Cover on Macroalgal Abundance on a Coral Reef in Belize. Marine Ecology Progress Series, 222, 187-196.

https://doi.org/10.3354/meps222187 
[36] Bennett, S. and Bellwood, D.R. (2011) Latitudinal Variation in Macroalgal Consumption by Fishes on the Great Barrier Reef. Marine Ecology Progress Series, 426, 241-252. https://doi.org/10.3354/meps09016

[37] Ehrlich, P.R. and Ehrlich, A.H. (1972) Coevolution: Heterotypic Schooling in Caribbean Reef Fishes. American Naturalist, 107, 157-160.

https://doi.org/10.1086/282823 